\title{
WYZNACZENIE MODALNEJ ODPOWIEDZI KONSTRUKCJI NA WSTRZĄSY Z UWZGLĘDNIENIEM KIERUNKÓW ICH DZIAŁANIA
}

\begin{abstract}
W referacie przedstawiono sposoby uwzględniania odpowiedzi modalnej konstrukcji na działanie wstrząsów sejsmicznych posługując się spektralną analizą modalną. Omówiono metodę spektrum odpowiedzi uwzględniając najważniejsze zalecenia dotyczące jej stosowania. Opisano najczęściej stosowaną metodę sumowania odpowiedzi modalnej - CQC oraz jej modyfikacje - metody CQC3 i GCQC3, które pozwalają uwzględnienie kierunków działania wstrząsu. Odniesiono się również do przepisów zawartych w normie Eurocode 8 dotyczących wytycznych sumowania odpowiedzi z różnych kierunków. Na przykładach numerycznych dokonano porównania zaprezentowanych metod z użyciem spektralnej analizy modalnej oraz obliczono odpowiedź wybranych sił przekrojowych.
\end{abstract}

Słowa kluczowe: analiza sejsmiczna, spektralna analiza modalna, kombinacje kwadratowe, wstrząsy wielokierunkowe, korelacja międzymodalna

\section{Wstęp}

Metoda spektrum odpowiedzi jest szeroko znana w literaturze dotyczącej działu budownictwa jakim jest inżynieria sejsmiczna. Stosuje się ją do wyznaczenia odpowiedzi budowli na drgania podłoża różnego pochodzenia - naturalnego, spowodowanego ruchem skorupy ziemskiej (drgania sejsmiczne) oraz spowodowanego działalnością człowieka (drgania parasejsmiczne). W metodzie tej stosowane jest wiele zagadnień z zakresu dynamiki budowli i stochastycznej teorii drgań, które mogą mieć ogromny wpływ na uzyskane wyniki obliczeń. W pracy omówiono ortogonalność działania kierunków wymuszenia oraz działanie wstrząsów pod różnym kątem w stosunku do usytuowania budowli.

Celem artykułu jest szczegółowe przedstawienie metod sumowania wpływów pomiędzy różnymi kierunkami wstrząsu. Na przykładzie dwóch konstrukcji stalowych wskazano różnice jakie można otrzymać w wartościach sił wewnętrznych stosując różne algorytmy superponowania odpowiedzi.

\footnotetext{
${ }^{1}$ Grzegorz Górnik, Politechnika Rzeszowska, Katedra Konstrukcji Budowlanych, ul. Poznańska 2, 35-084 Rzeszów, gornik.grzegorz@gmail.com
} 


\section{Metoda spektrum odpowiedzi i analiza dynamiczna}

Badając wpływ ruchów podłoża typu sejsmicznego lub parasejsmicznego na konstrukcję możemy posłużyć się wieloma metodami - siły poziomej, metodą spektrum odpowiedzi, oraz analizą czasową [15]. Metoda siły poziomej jest metodą, która posiada wiele ograniczeń, w głównej mierze nadaje się do zastosowania dla budynków o regularnym kształcie, analizuje się w niej tylko jedną, dominującą formę drgań własnych (brak kombinacji kwadratowych). Warunkiem jej stosowania jest normowe [3] ograniczenie odstępu kolejnych okresów drgań własnych konstrukcji.

W wyniku użycia tej metody możemy się spodziewać wyników z oszacowaniem od góry - przewymiarowanych. Kolejną poważną wadą metody jest konieczność analizy kilku kierunków wstrząsu w celu zapewnienia bezpieczeństwa konstrukcji, co sprowadza analizę do żmudnych i czasochłonnych obliczeń. Jest to metoda bardzo ogólna i nie będziemy się nią tutaj zajmować.

Metoda spektrum odpowiedzi wydaje się być odpowiednim podejściem, szczególnie z uwagi na możliwość użycia zaawansowanych programów obliczeniowych. Zaletą tego podejścia jest również możliwość utworzenia indywidualnego spektrum obliczeniowego posługując się posiadanymi danymi z akcelerogramów dla danego regionu [1].

\section{Sposoby sumowania odpowiedzi modalnej - kombinacje kwadratowe}

W większości przypadków główna odpowiedź konstrukcji może być wyznaczona przy uwzględnieniu kilku pierwszych postaci drgań własnych konstrukcji (giętnych i/lub skrętnych), pomijając te o wysokiej częstotliwości.

Istnieje wiele metod sumowania odpowiedzi modalnej konstrukcji o $n$ postaciach drgań własnych. Jedne z nich uwzględniają tylko główną postać drgań i na jej podstawie obliczają odpowiedź budynku, przez co zadanie obliczeniowe jest prostsze i mniej obciążające lecz może być mniej dokładne. Norma [3] postuluje, że jeśli okresy własne są odpowiednio od siebie oddalone co jest przedstawione przez nierówność (1),

$$
\mathrm{T}_{\mathrm{i}+1} \leq 0,9 \mathrm{~T}_{\mathrm{i}}
$$

to wszystkie odpowiedzi modalne mogą być traktowane niezależnie a do wyznaczenia całkowitej odpowiedzi, możemy użyć metody SRSS (Square Root of Sum of Squares) opisanej w $[15,16]$.

$\mathrm{W}$ przeciwnym razie zaleca się użycie innych procedur sumowania, ze wskazaniem na metodę QCQ. 


\section{Metoda Der Kiureghiana (CQC - Complete Quadratic Combination) [2]}

Wzory sumowania wyglądają następująco:

$$
\begin{aligned}
& \mathrm{R}_{\mathrm{CQC}, \max }=\sqrt{\sum_{\mathrm{i}=1}^{\mathrm{n}} \sum_{\mathrm{j}=1}^{\mathrm{n}} \mathrm{r}_{\mathrm{i}} \cdot \mathrm{P}_{\mathrm{ij}} \cdot \mathrm{r}_{\mathrm{j}}} \\
& \mathrm{P}_{\mathrm{ij}}=\frac{8 \sqrt{\xi_{\mathrm{i}} \xi_{\mathrm{j}}} \cdot\left(\xi_{\mathrm{i}}+\mathrm{r}_{\mathrm{j}}\right) \mathrm{a}^{1,5}}{\left(1-\mathrm{a}^{2}\right)^{2}+4 \xi_{\mathrm{i}} \xi_{\mathrm{j}} \mathrm{a}\left(1+\mathrm{a}^{2}\right)+4\left(\xi_{\mathrm{i}}^{2}+\xi_{\mathrm{j}}^{2}\right) \mathrm{a}^{2}}
\end{aligned}
$$

gdzie: $a=\min \left(\frac{T_{i}}{T_{j}}, \frac{T_{j}}{T_{i}}\right) \leq 1,0$

$\mathrm{R}_{\max }$ - maksymalna oszacowana odpowiedź wybranej wielkości $\mathrm{F}$

$\mathrm{r}_{\mathrm{i}}, \mathrm{r}_{\mathrm{j}}$ - maksymalna odpowiedź wielkości $\mathrm{r}$ dla i-tej i j-tej

częstotliwości drgań,

$\mathrm{n}$ - liczba rozpatrywanych częstości

$\mathrm{P}_{\mathrm{ij}}$ - macierz współczynników korelacji międzymodalnej

$\xi_{i}, \xi_{j}$ - współczynnik tłumienia krytycznego dla i-tej i j-tej częstotliwości drgań

Gdy przyjęta jest jedna wartość tłumienia $\xi_{\mathrm{i}}=\xi_{\mathrm{j}}=\xi$ to macierz współczynników korelacji międzymodalnej upraszcza się do postaci:

$$
\mathrm{P}_{\mathrm{ij}}=\frac{8 \xi^{2} \cdot(1+\mathrm{a}) \mathrm{a}^{1,5}}{\left(1-\mathrm{a}^{2}\right)^{2}+4 \xi^{2} \mathrm{a}(1+\mathrm{a})^{2}}
$$

Powszechnie wyznacza się tyle postaci drgań własnych aby relatywny udział drgającej masy konstrukcji przekroczył $90 \%$ w każdym kierunku drgań. Co więcej wszystkie postacie modalne, w których drga co najmniej 5\% całkowitej masy konstrukcji powinny być również uwzględnione.

\section{Efekty ortogonalne i wielokierunkowe działanie wstrząsów}

\subsection{Wstęp}

Projektując konstrukcję odporną na oddziaływania sejsmiczne powinno się przewidzieć wszystkie kierunki działania trzęsienia. Dla konstrukcji o nieregularnych kształtach lub zakrzywionych w planie wyznaczenie kierunku trzęsienia, które spowoduje największe wytężenie w danym elemencie czy punkcie konstrukcji nie jest oczywiste. Racjonalne jest założenie, że podczas wstrząsu dominuje jeden kierunek główny, który jednak dla większości wstrząsów nie jest znany i jest trudny do określenia. Powoduje to konieczność zaprojektowania 
konstrukcji odpornej na trzęsienie z każdego możliwego do wystąpienia kierunku. Należy również uwzględnić jednoczesne wystąpienie ruchów podłoża w kierunku prostopadłym do kierunku wiodącego [17].

Bazując na tych założeniach, konstrukcja powinna być odporna na ruchy podłoża w kierunku głównym 1 działającym pod dowolnym kątem $\theta$ do głównych osi konstrukcji oraz działającym w tym samym czasie kierunku 2 prostopadłym do 1 . Sytuację tą, wraz z naniesionym konturem budynku obrazuje rys. 1.

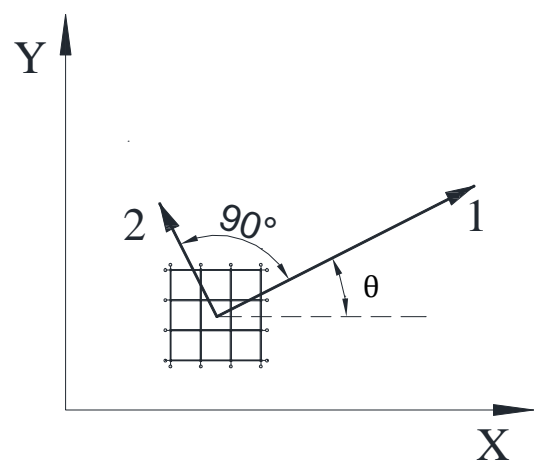

Rys. 1. Działanie trzęsienia ziemi w dwóch prostopadłych kierunkach pod kątem $\theta$ do osi konstrukcji; 1 - kierunek główny, 2 - kierunek towarzyszący wg [17]

Fig. 1. Earthquake movements in two perpendicular directions at an angle $\theta$ to the axis of the structure; 1 - main direction, 2 - associate direction, based on [17]

Zakładając, że magnituda $S_{2}$ trzęsienia prostopadłego do wstrząsu głównego $S_{1}$ jest jego częścią możemy zapisać:

$$
\mathrm{S}_{2}=\gamma_{2} \mathrm{~S}_{1} \text { oraz } \gamma \in(0 ; 1)
$$

Bazując na tym założeniu Menun i Der Kiureghian [10] zaprezentowali kombinację CQC3, która uwzględnia zmienność działania trzęsienia w planie.

\subsection{Metoda CQC3 (Complete Quadratic Combination for 3 directions)}

Podstawowe równania sumowania:

$$
R_{3 D, \max }=\sqrt{\left[\mathrm{r}_{\mathrm{x}}^{2}+\left(\gamma_{2} \mathrm{r}_{\mathrm{y}}\right)^{2}\right] \cos ^{2} \theta+\left[\mathrm{r}_{\mathrm{y}}^{2}+\left(\gamma_{2} \mathrm{r}_{\mathrm{x}}\right)^{2}\right] \sin ^{2} \theta+2\left(1-\gamma_{2}^{2}\right) \mathrm{r}_{\mathrm{xy}} \sin \theta \cos \theta+\mathrm{r}_{\mathrm{z}}^{2}}
$$

gdzie: $\mathrm{r}_{\mathrm{x}}^{2}=\sum_{\mathrm{n}} \sum_{\mathrm{m}} \mathrm{r}_{\mathrm{xn}} \mathrm{P}_{\mathrm{ij}} \mathrm{r}_{\mathrm{ym}}$,

$$
\begin{aligned}
& \mathrm{r}_{\mathrm{y}}^{2}=\sum_{\mathrm{n}} \sum_{\mathrm{m}} \mathrm{r}_{\mathrm{yn}} \mathrm{P}_{\mathrm{ij}} \mathrm{r}_{\mathrm{ym}}, \\
& \mathrm{r}_{\mathrm{xy}}=\sum_{\mathrm{n}} \sum_{\mathrm{m}} \mathrm{r}_{\mathrm{xn}} \mathrm{P}_{\mathrm{ij}} \mathrm{f}_{\mathrm{ym}}, \\
& \mathrm{r}_{\mathrm{z}}^{2}=\sum_{\mathrm{n}} \sum_{\mathrm{m}} \mathrm{r}_{\mathrm{zn}} \mathrm{P}_{\mathrm{ij}} \mathrm{r}_{\mathrm{zm}},
\end{aligned}
$$


$\mathrm{r}_{\mathrm{xn}}$ - modalna odpowiedź w kierunku X dla postaci i (j)

$\mathrm{r}_{\mathrm{yn}}$ - modalna odpowiedź w kierunku Y dla postaci i (j)

$\mathrm{r}_{\mathrm{zn}}-$ modalna odpowiedź $\mathrm{w}$ kierunku pionowym dla postaci i $(\mathrm{j})$

Dla $\gamma_{2}=1$ maksymalna odpowiedź wybranej wielkości R nie zależy od kąta $\theta$ a równanie przyjmuje postać:

$$
\mathrm{R}_{\max }=\mathrm{R}_{\mathrm{SRSS}^{*}}=\sqrt{\mathrm{r}_{\mathrm{x}}^{2}+\mathrm{r}_{\mathrm{y}}^{2}+\mathrm{r}_{\mathrm{z}}^{2}}
$$

Wskazuje to na zaprojektowanie elementów konstrukcji, które są odporne na wstrząs ze wszystkich możliwych kierunków. Jest to oczywiste przewymiarowanie gdyż kierunki składowych jednego wstrząsu równe między sobą co do wartości magnitudy nigdy nie zostały zarejestrowane. Należy zwrócić uwagę, że w literaturze redukcja kombinacji CQC3 do wzoru (8) jest często nazywana kombinacją SRSS (Square Root of Sum of Squares), co jest mylące, jakkolwiek maksymalna odpowiedź jest pierwiastkiem z sumy kwadratów. Odpowiedzi w trzech niezależnych kierunkach są już wyznaczone jako superpozycja odpowiedzi modalnych za pomocą wybranej kombinacji kwadratowej (np. SRSS lub CQC). Dla podkreślenia tego faktu przy wyznaczaniu odpowiedzi dla trzech prostopadłych kierunków sumowanie według wzoru (8) oznaczono jako SRSS*. Kąt $\theta$ powodujący maksymalną odpowiedź wynosi:

$$
\theta_{\mathrm{cr}}=\frac{1}{2} \tan ^{-1}\left[\frac{2 \mathrm{r}_{\mathrm{xy}}}{\mathrm{r}_{\mathrm{x}}^{2}-\mathrm{r}_{\mathrm{y}}^{2}}\right]
$$

W pracy [8] zaprezentowano metodę GCQC3, która uwzględnia działanie wszystkich trzech komponentów trzęsienia pod różnymi kątami do ortogonalnych osi konstrukcji X, Y oraz Z (rys. 2).

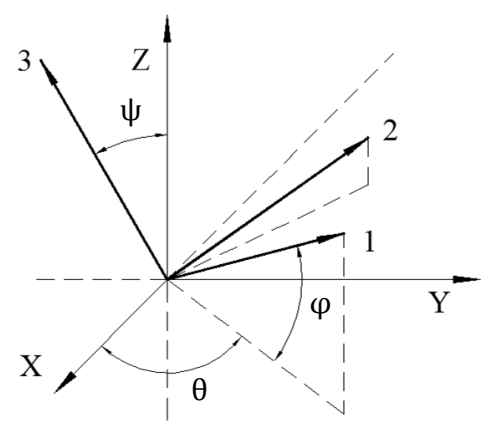

Rys. 2. Główne kierunki wstrząsu działającego pod różnymi kątami wg [8]

Fig. 2. Principal directions of the earthquake at various angles, based on [8] 


\subsection{Metoda GCQC3 (General Complete Quadratic Combination for 3 directions)}

Podstawowe równanie sumowania :

$$
\mathrm{R}_{\mathrm{cr}}(\theta, \varphi, \psi)=\sqrt{\sum_{\mathrm{k}=1}^{3} \gamma_{\mathrm{k}}^{2} \mathrm{u}_{\mathrm{k}}^{\mathrm{T}} \mathrm{Ru}_{\mathrm{k}}}
$$

Gdzie $\mathrm{u}_{1}, \mathrm{u}_{2}, \mathrm{u}_{3}$ to wektory jednostkowe odpowiadające kierunkom 1, 2 i 3 zgodnie ze wzorami poniżej:

$$
\begin{aligned}
& \mathrm{u}_{1}=\left[\begin{array}{c}
\cos \theta \cos \varphi \\
\sin \theta \cos \varphi \\
\sin \varphi
\end{array}\right] \\
& \mathrm{u}_{2}=\left[\begin{array}{c}
-\sin \theta \sec \varphi \cos \psi-\Delta \cos \theta \sin \varphi \\
\cos \theta \sec \varphi \cos \psi-\Delta \sin \theta \sin \varphi \\
\Delta \cos \varphi
\end{array}\right] \\
& \mathrm{u}_{3}=\left[\begin{array}{c}
-\cos \theta \tan \varphi \cos \psi+\Delta \sin \theta \\
-\sin \theta \tan \varphi \cos \psi-\Delta \cos \theta \\
\cos \psi
\end{array}\right] \\
& \Delta= \pm \cos \psi \sqrt{\tan ^{2} \psi-\tan ^{2} \varphi}
\end{aligned}
$$

$R$ jest macierzą odpowiedzi definiowaną jako:

$$
\begin{aligned}
& \mathrm{R}=\left[\begin{array}{lll}
\mathrm{r}_{\mathrm{xx}} & \mathrm{r}_{\mathrm{xy}} & \mathrm{r}_{\mathrm{xz}} \\
\mathrm{r}_{\mathrm{yx}} & \mathrm{r}_{\mathrm{yy}} & \mathrm{r}_{\mathrm{yz}} \\
\mathrm{r}_{\mathrm{zx}} & \mathrm{r}_{\mathrm{zy}} & \mathrm{r}_{\mathrm{zz}}
\end{array}\right] \\
& \mathrm{r}_{\mathrm{pq}}=\sum_{\mathrm{n}} \sum_{\mathrm{m}} \mathrm{r}_{\mathrm{pn}} \mathrm{P}_{\mathrm{ij}} \mathrm{r}_{\mathrm{qm}}
\end{aligned}
$$

gdzie: ( $p=X, Y$ lub Z); (q=X, Y lub Z)

Elementy na przekątnej macierzy $r_{x x}=r_{x}^{2}, r_{y y}=r_{y}^{2}$ i $r_{z z}=r_{z}^{2}$ są kwadratami maksymalnej odpowiedzi gdy komponent 1 trzęsienia działa wzdłuż osi $\mathrm{X}, \mathrm{Y}$ lub Z.

Dla każdego zestawu kątów $(\theta, \varphi, \psi)$ istnieją dwa zestawy wektorów jednostkowych $\mathrm{u}_{1}, \mathrm{u}_{2}$, $\mathrm{u}_{3}$ ze względu na znak równania (12). Oba rozwiązania muszą zostać rozważone przy wyznaczaniu odpowiedzi $R$, a poszukiwaną odpowiedzią jest największe $\mathrm{z}$ nich. W przypadku gdy komponenty 1, 2, 3 danego trzęsienia działa- 
ją odpowiednio wzdłuż osi X, Y, Z otrzymujemy $\theta=\varphi=\psi=0^{\circ}$ a wektory jednostkowe przyjmują postać $\mathrm{u}_{1}=\operatorname{col}[1,0,0], \mathrm{u}_{2}=\operatorname{col}[0,1,0], \mathrm{u}_{3}=\operatorname{col}[0,0,1]$.

Po podstawieniu do równania (10) otrzymujemy szczególny przypadek w metodzie GCQC3, który jest odmianą sumowania SRSS*.

$$
\mathbf{R}_{\mathrm{cr}}\left(\theta=\varphi=\psi=0^{\circ}\right)=\sqrt{\mathrm{r}_{\mathrm{x}}^{2}+\left(\gamma_{2} \mathrm{r}_{\mathrm{y}}\right)^{2}+\left(\gamma_{3} \mathrm{r}_{\mathrm{z}}\right)^{2}}=\mathbf{R}_{\mathrm{SRSS}^{*}}
$$

Liczba $\alpha_{n m}$ jest współczynnikiem korelacji odpowiedzi w kierunku n oraz m i jest określona równaniem (16). Pokazuje ona wrażliwość na odchylenie kierunku działania trzęsienia od osi X, Y lub Z.

$$
\alpha_{p q}=\frac{r_{p q}}{r_{p} \cdot r_{q}}
$$

Kąt $\psi_{\text {cr }}$ odchylenia komponentu pionowego dający maksymalną odpowiedź jest określony podobnie jak w metodzie CQC3.

$$
\psi_{\mathrm{cr}}=\frac{1}{2} \tan ^{-1}\left[\frac{2 \mathrm{r}_{\mathrm{xz}}}{\mathrm{r}_{\mathrm{x}}^{2}-\mathrm{r}_{\mathrm{z}}^{2}}\right]
$$

Odpowiedź krytyczna $\mathrm{R}_{\mathrm{cr}}$ jest największą spośród wyznaczonych wartości $\mathrm{R}$, dla wszystkich możliwych kątów działania wstrząsu, uwzględniając dwie wartości $\Delta$. W pracach $[8,9]$ na podstawie analizy 97 trzęsień ziemi określono zakres zmienności kąta $\psi$ dla rzeczywistych wstrząsów. Norma [3] podaje natomiast wzory, które nie uwzględniają zmienności kątowej poszczególnych składowych trzęsienia i mogą być stosowane do sumowania wpływów pomiędzy kierunkami.

$$
\left\{\begin{array}{l}
\mathrm{E}_{\mathrm{dx}}+0,30 \mathrm{E}_{\mathrm{dy}}+0,30 \mathrm{E}_{\mathrm{dz}} \\
0,30 \mathrm{E}_{\mathrm{dx}}+\mathrm{E}_{\mathrm{dy}}+0,30 \mathrm{E}_{\mathrm{dz}} \\
0,30 \mathrm{E}_{\mathrm{dx}}+0,30 \mathrm{E}_{\mathrm{dy}}+\mathrm{E}_{\mathrm{dz}}
\end{array}\right.
$$

gdzie: $\mathrm{E}_{\mathrm{dx}}, \mathrm{E}_{\mathrm{dy}}, \mathrm{E}_{\mathrm{dz}}$ - odpowiedź sejsmiczna odpowiednio wzdłuż osi $\mathrm{X}, \mathrm{Y}, \mathrm{Z}$ konstrukcji (znak + wg normy oznacza skombinowanie odpowiedzi w poszczególnych kierunkach).

Są one oparte na propozycji Newmarka, gdzie ogólna zasada uwzględnienia różnych kierunków wymuszenia jest przedstawiona jako:

$$
\pm \mathrm{R}_{\text {max }}=\left\{\begin{array}{l} 
\pm \mathrm{F}_{1} \pm \alpha \mathrm{F}_{2} \pm \beta \mathrm{F}_{3} \\
\pm \alpha \mathrm{F}_{1} \pm \mathrm{F}_{2} \pm \beta \mathrm{F}_{3} \\
\pm \alpha \mathrm{F}_{1} \pm \beta \mathrm{F}_{2} \pm \mathrm{F}_{3}
\end{array}\right.
$$


gdzie: $F_{1}, F_{2}, F_{3}$ - odpowiedź sejsmiczna w trzech analizowanych kierunkach.

W większości norm i przepisów $[3,14] \alpha=\beta=\left\{\begin{array}{l}0,3 \\ 0,4\end{array}\right.$, co oznacza, że brane jest pod uwagę $30 \%$ lub $40 \%$ odpowiedzi w towarzyszących kierunkach prostopadłych.

\section{Przykłady obliczeniowe}

\subsection{Wyznaczenie odpowiedzi za pomocą metody normowej wg [1]}

Na przykładzie stalowego budynku o konstrukcji ramowej, pokazanego na rys. 3 i rys. 4 dokonano porównania przedstawionych algorytmów a wyniki przedstawiono poniżej. Ramy budynku w kierunku Y o węzłach sztywnych, w kierunku X o węzłach przegubowych. Słupy utwierdzone w fundamencie. Stężenia występują tylko na kierunku X w skrajnych ramach w osi A oraz D. Elementy ze stali klasy S355. W analizie modalnej wyznaczono 85 postaci drgań własnych. Procent udziału mas w obu kierunkach przekroczył $90 \%$ i wyniósł dla kierunku X 94,43\% i dla kierunku Y 97,93\%. Użyto konwersji obciążeń stałych. W analizie spektralnej zastosowano obliczeniowe spektrum odpowiedzi typu II dla gruntu klasy D wg [3,5]. Wymuszenie kinematyczne działa w kierunkach $\mathrm{X}$, Y oraz Z. Zgodnie z EC8 pomiędzy kierunkami użyto kombinacji Newmarka ze współczynnikiem 0,30 . Dla każdego kierunku z osobna odpowiedź modalną sumowano kombinacją kwadratową typu CQC (rys. 5).

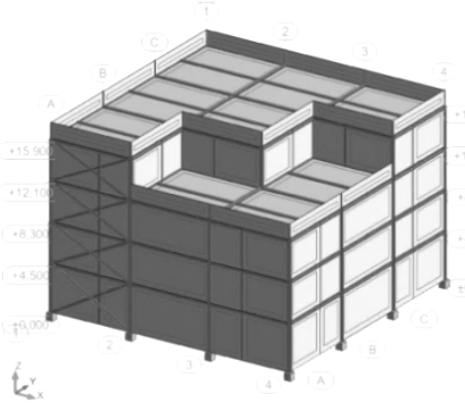

Rys. 3. Widok przestrzenny analizowanej konstrukcji

Fig. 3. Spatial view of analyzed structure

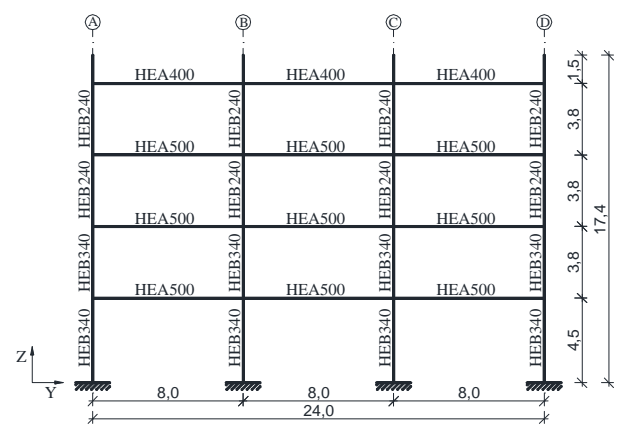

Rys. 4. Rama w osi 2 wraz z oznaczeniem przekrojów prętów i podstawowymi wymiarami

Fig. 4. Frame in axis 2 with dimensions and sections 


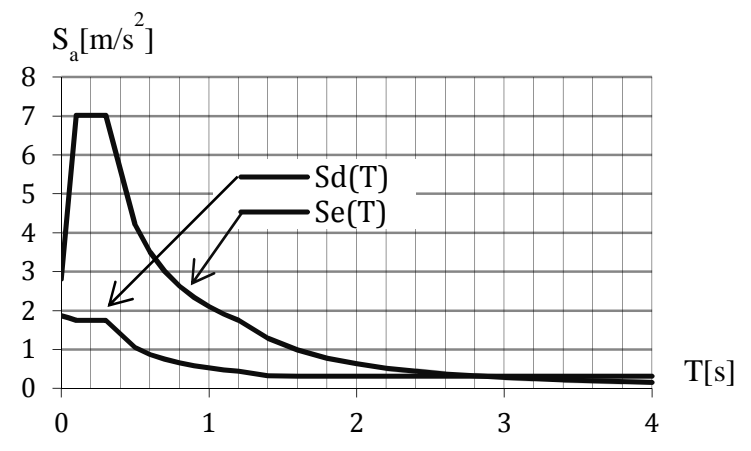

Rys. 5. Wykresy sprężystego i obliczeniowego spektrum odpowiedzi dla przyjętego typu gruntu

Fig. 5. Diagrams of elastic and design spectra for the selected type of ground

Poniżej przedstawiono wykresy momentów w słupach parteru dla kombinacji Y+0.3X-0.3Z (rys. 6).

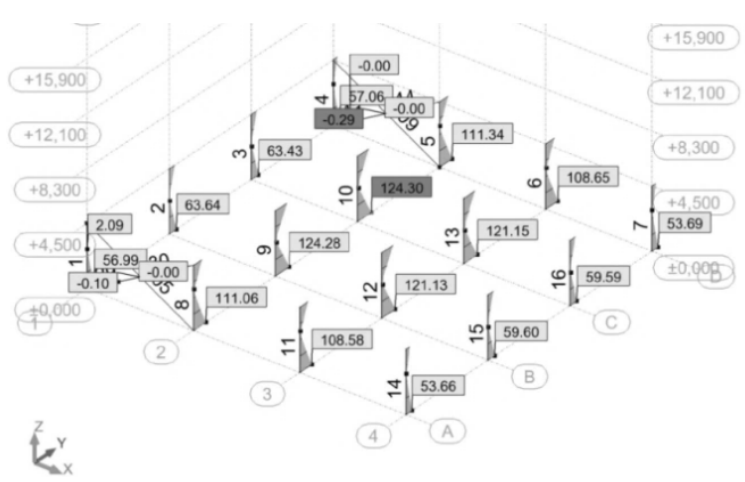

Rys. 6. Wykresy momentów zginających słupy parteru gdy główny komponent wstrząsu działa w kierunku Y (kombinacja $\mathrm{Y}+0.3 \mathrm{X}-0.3 \mathrm{Z}$ )

Fig. 6. Bending moments in columns (level 0) with the principal magnitude in $\mathrm{Y}$ direction (kombination $\mathrm{Y}+0.3 \mathrm{X}-0.3 \mathrm{Z}$ )

Do dalszej analizy wybrano pręt nr 10 i przedstawiono zestawienie sił w węźle podporowym $\mathrm{w}$ zależności od ortogonalnego kierunku działania trzęsienia (tab. 1). Ponieważ nie ma jasno określonych zasad sumowania odpowiedzi od wszystkich wpływów w tabeli 2 zestawiono wszystkie 24 permutacje kombinacji Newmarka zgodnie ze wzorem (19). Maksymalne wartości wyniosły $\pm 201,83 \mathrm{kN}$ dla siły osiowej $\mathrm{i} \pm 128,71 \mathrm{kNm}$ dla momentu podporowego $\mathrm{My}$. 
Tabela. 1. Wybrane siły w węźle podporowym słupa nr 10

Table. 1. Selected internal forces in the supporting node of column no. 10

\begin{tabular}{|c|c|c|}
\hline $\begin{array}{c}\text { Kierunek } \\
\text { trzęsienia }\end{array}$ & $\mathrm{N}[\mathrm{kN}]$ & $\mathrm{My}[\mathrm{kNm}]$ \\
\hline $\mathrm{X}$ & 13,64 & 7,33 \\
\hline $\mathrm{Y}$ & 16,41 & 125,82 \\
\hline $\mathrm{Z}$ & 192,81 & 2,29 \\
\hline
\end{tabular}

Tabela. 2. Wszystkie możliwe permutacje kombinacji Newmarka dla słupa nr 10

Table. 2. All possible permutations of Newmark combination for column 10

\begin{tabular}{|c|c|c|c|}
\hline \multicolumn{2}{|r|}{ Permutacja } & $\mathrm{N}[\mathrm{kN}]$ & My $[\mathrm{kNm}]$ \\
\hline 1 & $\mathrm{X}+0,3 \mathrm{Y}+0,3 \mathrm{Z}$ & 76,41 & 45,76 \\
\hline 2 & $\mathrm{X}+0,3 \mathrm{Y}-0,3 \mathrm{Z}$ & $-39,28$ & 44,39 \\
\hline 3 & $\mathrm{X}-0,3 \mathrm{Y}+0,3 \mathrm{Z}$ & 66,56 & $-29,73$ \\
\hline 4 & $X-0,3 Y-0,3 Z$ & $-49,13$ & $-31,10$ \\
\hline 5 & $-\mathrm{X}+0,3 \mathrm{Y}+0,3 \mathrm{Z}$ & 49,13 & 31,10 \\
\hline 6 & $-\mathrm{X}+0,3 \mathrm{Y}-0,3 \mathrm{Z}$ & $-66,56$ & 29,73 \\
\hline 7 & $-\mathrm{X}-0,3 \mathrm{Y}+0,3 \mathrm{Z}$ & 39,28 & $-44,39$ \\
\hline 8 & $-\mathrm{X}-0,3 \mathrm{Y}-0,3 \mathrm{Z}$ & $-76,41$ & $-76,41$ \\
\hline 9 & $\mathrm{Y}+0,3 \mathrm{Y}+0,3 \mathrm{X}$ & 78,35 & 128,71 \\
\hline 10 & $Y+0,3 Z-0,3 X$ & 70,16 & 124,31 \\
\hline 11 & $Y-0,3 Z+0,3 X$ & $-37,34$ & 127,33 \\
\hline 12 & $Y-0,3 Z-0,3 X$ & $-45,53$ & 122,93 \\
\hline 13 & $-Y+0,3 Z+0,3 X$ & 45,53 & $-122,93$ \\
\hline 14 & $-Y+0,3 Z-0,3 X$ & 37,34 & $-127,33$ \\
\hline 15 & $-Y-0,3 Z+0,3 \mathrm{X}$ & $-70,16$ & $-124,31$ \\
\hline 16 & -Y-0,3Z-0,3X & $-78,35$ & $-128,71$ \\
\hline 17 & $\mathrm{Z}+0,3 \mathrm{X}+0,3 \mathrm{Y}$ & 201,83 & 42,24 \\
\hline 18 & $\mathrm{Z}+0,3 \mathrm{X}-0,3 \mathrm{Y}$ & 191,98 & $-33,26$ \\
\hline 19 & $\mathrm{Z}-0,3 \mathrm{X}+0,3 \mathrm{Y}$ & 193,64 & 37,84 \\
\hline 20 & $\mathrm{Z}-0,3 \mathrm{X}-0,3 \mathrm{Y}$ & 183,80 & $-37,66$ \\
\hline 21 & $-\mathrm{Z}+0,3 \mathrm{X}+0,3 \mathrm{Y}$ & $-183,80$ & 37,66 \\
\hline 22 & $-\mathrm{Z}+0,3 \mathrm{X}-0,3 \mathrm{Y}$ & $-193,64$ & $-37,84$ \\
\hline 23 & $-\mathrm{Z}-0,3 \mathrm{X}+0,3 \mathrm{Y}$ & $-191,98$ & 33,26 \\
\hline 24 & $-Z-0,3 X-0,3 Y$ & $-201,83$ & $-42,24$ \\
\hline & Ekstrema & $\pm 201,8$ & $\pm 128,71$ \\
\hline
\end{tabular}

Wartości te powinny zostać użyte przy sprawdzeniu warunku nośności w 4 sejsmicznych przypadkach kombinacyjnych przy innych oddziaływaniach (ciężar stały, obciążenia zmienne).

$$
\begin{array}{ll}
M_{y, \text { max }}^{\text {sei }}+N_{\text {min }}^{\text {sei }} & M_{y, \text { min }}^{\text {sei }}+N_{\text {min }}^{\text {sei }} \\
M_{y, \text { max }}^{\text {sei }}+N_{\text {max }}^{\text {sei }} & M_{y, \text { min }}^{\text {sei }}+N_{\text {max }}^{\text {sei }}
\end{array}
$$


Korzystając ze wzoru na pierwiastek z sumy kwadratów dla analizowanych sił otrzymujemy:

$$
\begin{aligned}
& \mathrm{R}_{\mathrm{N}}=\mathrm{R}_{\mathrm{SRSS}^{*}}=\sqrt{\mathrm{r}_{\mathrm{x}}^{2}+\mathrm{r}_{\mathrm{y}}^{2}+\mathrm{r}_{\mathrm{z}}^{2}}=193,98 \mathrm{kN} \\
& \mathrm{R}_{\mathrm{M}}=\mathrm{R}_{\mathrm{SRSS}^{*}}=\sqrt{\mathrm{r}_{\mathrm{x}}^{2}+\mathrm{r}_{\mathrm{y}}^{2}+\mathrm{r}_{\mathrm{z}}^{2}}=126,05 \mathrm{kNm}
\end{aligned}
$$

które to wartości są mniejsze niż przy wykorzystaniu metody normowej o 4,0\% i 2,1\% odpowiednio dla siły osiowej i momentu zginającego.

W celu zweryfikowania czy kombinacja sugerowana przez normę [3] jest zawsze konserwatywna w stosunku do metody pierwiastka z sumy kwadratów przekształcono wzory (8) i (18) do postaci

$$
\begin{aligned}
& \mathrm{r}_{\max }=\sqrt{1,0+\mathrm{r}_{1}^{2}+\mathrm{r}_{2}^{2}} \\
& \mathrm{r}_{\max }=1,0+0,3 \mathrm{r}_{1}+0,3 \mathrm{r}_{2}
\end{aligned}
$$

gdzie $r_{\max }=\frac{R}{r_{x}}, r_{1}=\frac{r_{y}}{r_{x}}, r_{2}=\frac{r_{z}}{r_{x}}$ są znormalizowanymi odpowiedziami dla każdego z kierunków. Porównania dokonano za pomocą funkcji określonej równaniem (22) a wykres pokazano na rys. 7.

$$
\mathrm{f}\left(\mathrm{r}_{1}, \mathrm{r}_{2}\right)=\frac{1,0+0,3 \mathrm{r}_{1}+0,3 \mathrm{r}_{2}}{\sqrt{1,0+\mathrm{r}_{1}^{2}+\mathrm{r}_{2}^{2}}}-1
$$
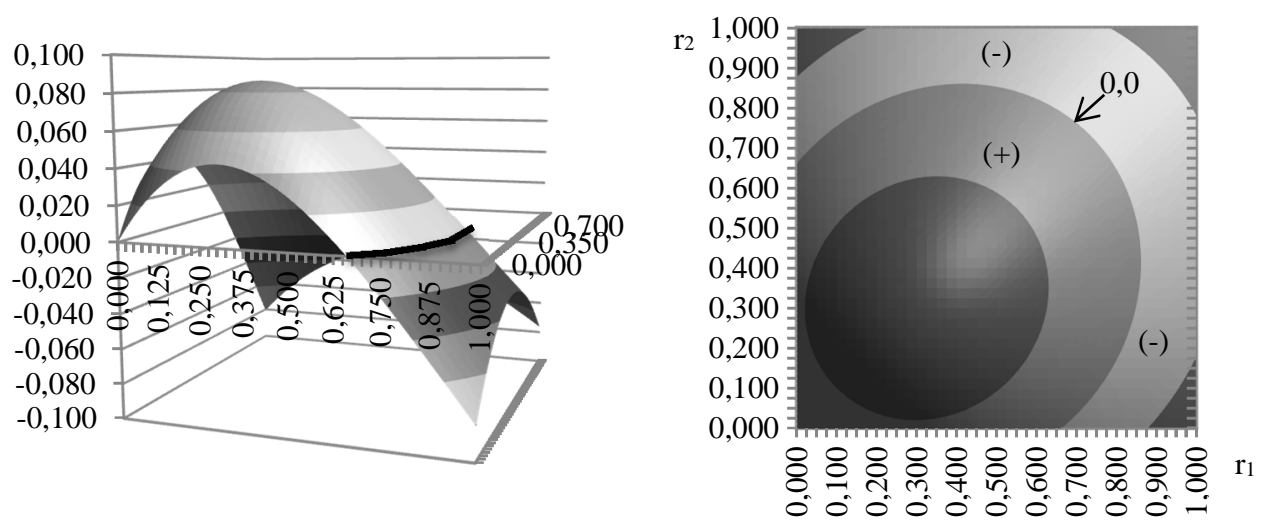

Rys. 7. Porównanie metody Newmarka z 30\% udziałem kierunków towarzyszących z klasyczną metodą SRSS*

Fig. 7. Comparison of the Newmark method (100-30-30) with SRSS* method 
Strzałką wskazano linię o wartości 0,00 odgraniczającą obszar dla którego odpowiedź elementu wyznaczona za pomocą sumowania SRSS* (wzór 8) jest mniejsza niż ta wyznaczona za pomocą wzoru normowego. Wahania mają się w zakresie $\pm 8,3 \%$. Prawdopodobieństwo niedoszacowania odpowiedzi jest bardzo duże i wynosi około $43 \%$, co równa się powierzchni obszaru ujemnego. Podobne postępowanie przeprowadzono w pracy [7].

\subsection{Wyznaczenie odpowiedzi za pomocą metody GCQC3}

W metodzie GCQC3 obliczono wartość momentu My w węźle 71 oraz siły osiowej w węźle 205 konstrukcji przedstawionej na rys. 8. Jest to konstrukcja wsporcza suszarni rozpyłowej znajdująca się w istniejącej hali. Uwzględniono zależności trzech komponentów trzęsienia i kątów jakie mogą tworzyć z głównymi osiami konstrukcji. Wykonano analizę modalną z konwersją obciążeń stałych oraz analizę spektralną używając obliczeniowego spektrum odpowiedzi jak na rys. 5.

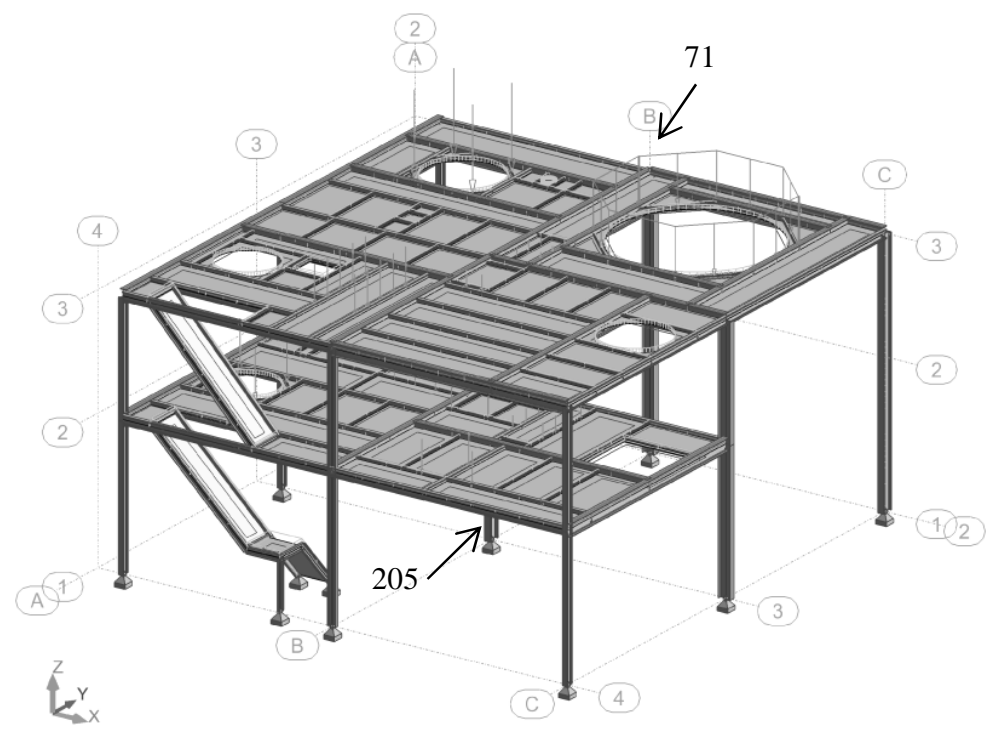

Rys. 8. Model konstrukcji wsporczej ze wskazaniem analizowanych węzłów

Fig. 8. Model of support structure with indication of analyzed nodes

W celu wyznaczenia składników macierzy ze wzoru (13) wykonano obliczenia jej składników zgodnie ze wzorami metody CQC. Poniżej przedstawiono obliczenia tylko dla składnika $r_{z z}$.

Analizowano 50 częstotliwości drgań własnych i wybrano te, które niosą najwięcej masy w poszczególnych kierunkach. Wyniki zestawiono w tabeli 3. 
Tabela. 3. Wybrane siły w węźle podporowym nr 205

Table. 3. Selected forces in supporting node no. 205

\begin{tabular}{|c|c|c|c|}
\hline $\begin{array}{c}\text { Forma } \\
\text { drgań }\end{array}$ & $\begin{array}{c}\text { Kierunek } \\
\text { drgań }\end{array}$ & Okres $\mathrm{T}[\mathrm{s}]$ & $\begin{array}{c}\text { Wybrana wielkość } \\
\text { statyczna: } \mathrm{N}_{\mathrm{i}}^{205}[\mathrm{kN}]\end{array}$ \\
\hline 1 & $\mathrm{X}$ & 1,78 & 0,02 \\
\hline 2 & $\mathrm{Y}$ & 1,49 & 0,02 \\
\hline 21 & $\mathrm{Z}$ & 0,20 & 3,58 \\
\hline 28 & $\mathrm{Z}$ & 0,16 & 3,63 \\
\hline 33 & $\mathrm{Z}$ & 0,15 & 2,22 \\
\hline
\end{tabular}

Na rys. 9 przedstawiono kształt drgań dla formy 1, 2, 21 i 28.

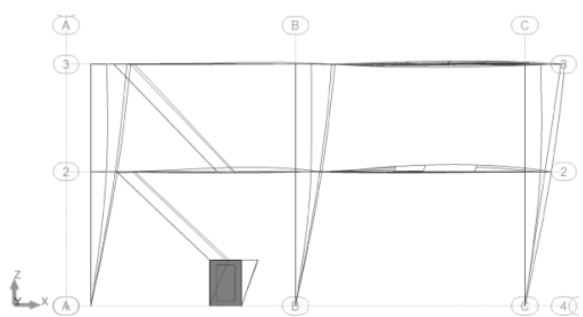

Forma drgań nr 1 (X)

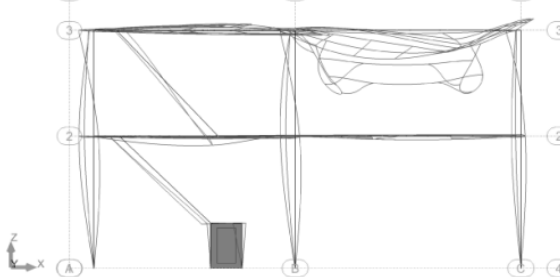

Forma drgań nr $21(\mathrm{Z})$

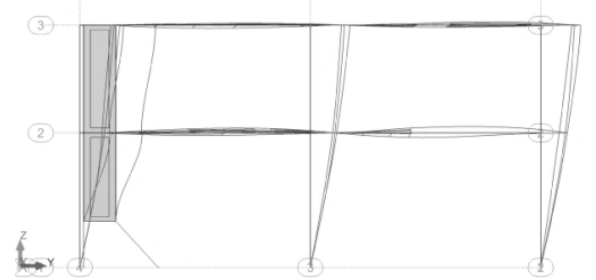

Forma drgań nr 2 (Y)

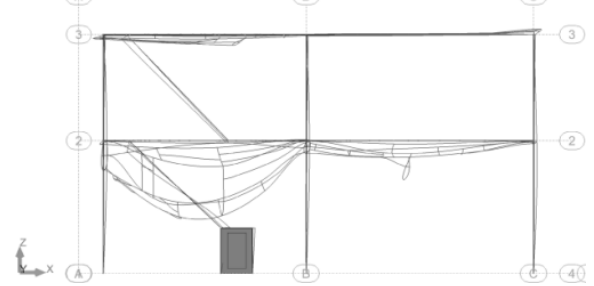

Forma drgań nr $28(\mathrm{Z})$

Rys. 9. Formy drgań własnych analizowanej konstrukcji

Fig. 9. Natural vibration forms of the analyzed structure

Poniżej przedstawiono macierz A współczynnika $a=\min \left(\frac{T_{i}}{T_{j}}, \frac{T_{j}}{T_{i}}\right)$, macierz korelacji międzymodalnej $\mathrm{P}_{\mathrm{ij}}$ oraz macierz reakcji $\mathrm{R}_{\mathrm{z}, \mathrm{CQC}}$ siły osiowej $\mathrm{w}$ środkowym słupie. Analizując 5 wiodących form drgań mają one wymiar 5x5.

$\mathrm{A}=\left[\begin{array}{lllll}1,00 & 0,84 & 0,11 & 0,09 & 0,08 \\ 0,84 & 1,00 & 0,13 & 0,11 & 0,10 \\ 0,11 & 0,13 & 1,00 & 0,80 & 0,75 \\ 0,09 & 0,11 & 0,80 & 1,00 & 0,94 \\ 0,08 & 0,10 & 0,75 & 0,94 & 1,00\end{array}\right], \quad \mathrm{P}_{\mathrm{ij}}=\left[\begin{array}{lllll}1,00 & 0,24 & 0,00 & 0,00 & 0,00 \\ 0,24 & 1,00 & 0,00 & 0,00 & 0,00 \\ 0,00 & 0,00 & 1,00 & 0,17 & 0,11 \\ 0,00 & 0,00 & 0,17 & 1,00 & 0,71 \\ 0,00 & 0,00 & 0,11 & 0,71 & 1,00\end{array}\right]$ 


$\mathrm{R}_{\mathrm{z}, \mathrm{CQC}}=\left[\begin{array}{ccccc}0,00 & 0,00 & 0,00 & 0,00 & 0,00 \\ 0,00 & 0,00 & 0,00 & 0,00 & 0,00 \\ 0,00 & 0,00 & 12,82 & 2,15 & 0,84 \\ 0,00 & 0,00 & 2,15 & 13,18 & 5,69 \\ 0,00 & 0,00 & 0,84 & 5,69 & 4,93\end{array}\right]$

Maksymalna siła osiowa w węźle 205 jest określona ze wzoru (2) i jest jednocześnie pierwiastkiem składnika $\mathrm{r}_{\mathrm{zz}}$ :

$$
\mathrm{N}_{\text {max }}=\mathrm{R}_{\mathrm{CQC}, \text { max }}=\sqrt{\sum_{\mathrm{i}=1}^{\mathrm{n}} \sum_{\mathrm{j}=1}^{\mathrm{n}} \mathrm{N}_{\mathrm{i}} \cdot \mathrm{P}_{\mathrm{ij}} \cdot \mathrm{N}_{\mathrm{j}}}=6,95 \mathrm{kN}=\mathrm{r}_{\mathrm{z}} \rightarrow \mathrm{r}_{\mathrm{zz}}=\mathrm{r}_{\mathrm{z}}^{2}=48,28
$$

Podobnie obliczono kolejne składniki a macierz odpowiedzi określona równaniem (13) wgląda następująco:

$$
\mathrm{R}=\left[\begin{array}{lll}
\mathrm{r}_{\mathrm{xx}} & \mathrm{r}_{\mathrm{xy}} & \mathrm{r}_{\mathrm{xz}} \\
\mathrm{r}_{\mathrm{yx}} & \mathrm{r}_{\mathrm{yy}} & \mathrm{r}_{\mathrm{yz}} \\
\mathrm{r}_{\mathrm{zx}} & \mathrm{r}_{\mathrm{zy}} & \mathrm{r}_{\mathrm{zz}}
\end{array}\right]=\left[\begin{array}{ccc}
20,52 & -2,80 & 0,25 \\
-2,80 & 5,90 & -1,33 \\
0,25 & -1,33 & 48,28
\end{array}\right]
$$

Zgodnie $\mathrm{z}$ wytycznymi [3] przyjęto $\gamma_{2}=\gamma_{3}=0,30$. Wybrane obliczenia przedstawiono dla następujących kątów $\theta=0^{\circ}, \varphi=10^{\circ}, \psi=20^{\circ}$. Współczynnik $\Delta$ przyjmuje dwie wartości jak poniżej:

$$
\Delta= \pm \cos \psi \sqrt{\tan ^{2} \psi-\tan ^{2} \varphi}= \pm 0,30
$$

Otrzymujemy dwa zestawy wektorów jednostkowych dla tych wartości:

$$
\begin{array}{rlrl}
\mathrm{u}_{1} & =\left[\begin{array}{l}
0,85 \\
0,49 \\
0,17
\end{array}\right] & \mathrm{u}_{1} & =\left[\begin{array}{c}
0,85 \\
0,49 \\
0,17
\end{array}\right] \\
\mathrm{u}_{2}=\left[\begin{array}{c}
-0,52 \\
1,00 \\
0,00
\end{array}\right] & \text { oraz } & \mathrm{u}_{2}=\left[\begin{array}{c}
-0,43 \\
0,85 \\
-0,29
\end{array}\right] \\
\mathrm{u}_{3}=\left[\begin{array}{c}
0,01 \\
-0,34 \\
0,94
\end{array}\right] & & \mathrm{u}_{3}=\left[\begin{array}{c}
-0,29 \\
0,18 \\
0,94
\end{array}\right]
\end{array}
$$

Maksymalna reakcja uwzględniającą kąty poszczególnych składowych trzęsienia zgodnie ze wzorem (10) wynosi:

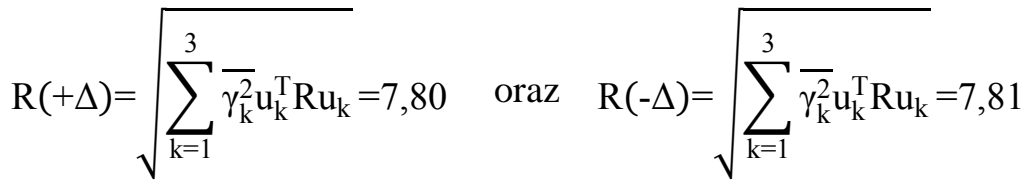

Poszukiwaną wartością jest zawsze większa z wyliczonych liczb, w naszym przypadku:

$$
\mathrm{R}_{\max }=\max [\mathrm{R}(+\Delta), \mathrm{R}(-\Delta)]=7,81 \mathrm{kN}
$$


Analogiczne obliczenia przeprowadzono dla różnej konfiguracji kątów, z założeniem że $\theta \epsilon(0 ; 360)^{\circ}, \varphi \epsilon(0,20)^{\circ}, \psi=20^{\circ}$ a wyniki przedstawiono poniżej dla analizowanej siły osiowej i momentu zginającego (rys. 10-11, tab. 4-5).

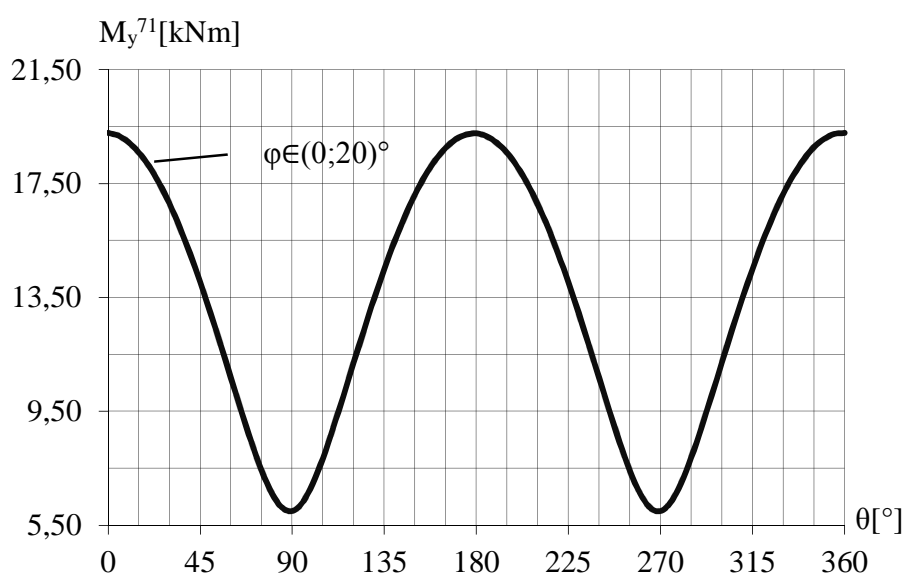

Rys. 10. Maksymalna wartości momentu zginającego (węzeł 71) w funkcji kąta $\theta$ oraz $\varphi\left(\psi=20^{\circ}\right)$

Fig. 10. Maximum value of bending moment (node 71) in relation to $\theta$ and $\varphi$ angles $\left(\psi=20^{\circ}\right)$

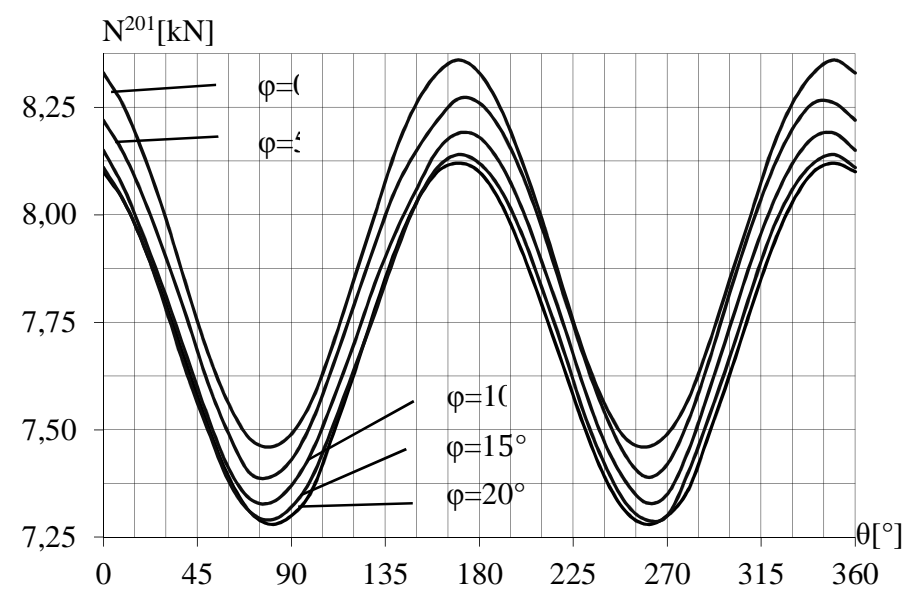

Rys. 11. Maksymalna wartości siły osiowej (węzeł 205) w funkcji kąta $\theta$ oraz $\varphi\left(\psi=20^{\circ}\right)$

Fig. 11. Maximum value of axial force (node 205) in relation to $\theta$ and $\varphi$ angles $\left(\psi=20^{\circ}\right)$ 
Tabela. 4. Wartości wybranych sił przekrojowych w zależności od kierunku wstrząsu

Table. 4. Values of selected internal forces with respect to direction of the earthquake

\begin{tabular}{|c|c|c|c|c|c|c|c|}
\cline { 2 - 8 } \multicolumn{1}{c|}{} & $\mathrm{r}_{\mathrm{x}}$ & $\mathrm{r}_{\mathrm{y}}$ & $\mathrm{r}_{\mathrm{z}}$ & $\alpha_{\mathrm{xy}}$ & $\alpha_{\mathrm{xz}}$ & $\theta_{\mathrm{cr}}$ & $\Psi_{\mathrm{cr}}$ \\
\hline $\mathrm{N}$ & 4,53 & 2,44 & 6,95 & $-0,25$ & $7,94 \cdot 10^{-3}$ & $-10,4^{\circ}$ & $-0,5^{\circ}$ \\
\hline $\mathrm{My}$ & 19,32 & 1,46 & 1,79 & $-0,28$ & $-5,78 \cdot 10^{-4}$ & $-1,2^{\circ}$ & $0,31^{\circ}$ \\
\hline
\end{tabular}

Tabela. 5. Porównanie maksymalnych wartości odpowiedzi spektralnej

Table. 5. Comparison of the maximum values of spectral response

\begin{tabular}{|c|c|c|c|c|c|}
\cline { 2 - 6 } \multicolumn{1}{c|}{} & $\mathrm{R}_{\mathrm{cr}}$ & $\mathrm{R}_{\text {SRSS }}$ & $\frac{\mathrm{R}_{\text {SRSS }}}{\mathrm{r}_{\mathrm{i}, \max }}$ & $\frac{\mathrm{R}_{\mathrm{cr}}}{\mathrm{r}_{\mathrm{i}, \mathrm{max}}}$ & $\frac{\mathrm{R}_{\mathrm{cr}}}{\mathrm{R}_{\text {SRSS }}}$ \\
\hline $\mathrm{N}$ & 8,36 & 7,12 & 1,02 & 1,20 & 1,17 \\
\hline $\mathrm{My}$ & 19,34 & 19,33 & 1,00 & 1,00 & 1,00 \\
\hline
\end{tabular}

\section{Wnioski}

Mając do wyboru różne rodzaje analiz sejsmicznych należy rozważyć wszystkie ich zalety i wady. Czas obliczeń, ich dokładność oraz możliwe do uzyskania wyniki mogą znacząco się różnić ze względu na indywidualną specyfikę zachowania każdej konstrukcji, wybór odpowiedniej kombinacji kwadratowej oraz metody uwzględnienia poszczególnych komponentów trzęsienia.

W referacie przedstawiono opis metod sumowania odpowiedzi modalnej, które wydają się być najbardziej uniwersalne. Niektóre z nich jeszcze nie zostały zaimplementowane do najbardziej popularnych programów obliczeniowych (GCQC3).

Na podstawie analiz przedstawionych w [8,9] można stwierdzić że wartości współczynników $\alpha$ i $\beta$ stosowane w kombinacji Newmarka pomiędzy kierunkami są praktycznie zawsze mniejsze niż to wynika $\mathrm{z}$ analiz różnych trzęsień. Co więcej porównując sposób Newmarka z klasyczną metodą SRSS* możemy uzyskać wyniki różniące się o ok. $\pm 8,3 \%$ a prawdopodobieństwo niedoszacowania jest bardzo duże i wynosi ok. 43\% (rys. 7). Pokazuje to jak ważny jest wybór metody sumowania pomiędzy kierunkami. Bezpiecznym wydaje się być podejście stosowane w normie amerykańskiej ASCE 4-98, gdzie współczynniki metody Newmarka wynoszą $\alpha=\beta=0,4$, błąd niedoszacowania odpowiedzi modalnej wynosi ok $1,0 \%$ a prawdopodobieństwo jego osiągnięcia wynosi ok. $0,18 \%$ [7]. W drugim przykładzie w celu uwzględnienia w analizie odchylenia poszczególnych składowych trzęsienia użyto metody GCQC3. W zależności od wybranej siły wewnętrznej całkowita odpowiedź sejsmiczna równała się odpowiedzi wyznaczonej metodą SRSS* (moment My) lub była od niej o 17\% większa (siła osiowa $\mathrm{N}$ ). Wynika to bezpośrednio $\mathrm{z}$ wartości współczynnika korelacji $\alpha_{\mathrm{pq}}$ i odchylenia poszczególnych składowych wstrząsu. Największą wrażliwość na zmianę kąta zaobserwowano w obliczeniach odpowiedzi siły osiowej, gdzie 
krytyczny kąt wynosił $\theta_{\mathrm{cr}}=-10,4^{\circ}$. Na rys. 10 i 11 pokazano zależność maksymalnej odpowiedzi modalnej od kątów $\theta$ i $\varphi$ dla stałej wartości $\psi=20^{\circ}$. Możemy zauważyć, że wartość momentu zginającego $\mathrm{M}_{\mathrm{y}}$ zależy tylko od kąta $\theta$ natomiast wartość siły osiowej w słupie jest bardziej wrażliwa na zmianę kierunków wstrząsu.

\section{Literatura}

[1] Czerwonka L., Tatara T.: Wzorcowe spektra odpowiedzi z wybranych obszarów GZW. Czasopismo Techniczne Politechniki Krakowskiej, z. 2-B/2007.

[2] Der Kiureghian A.: On response of structures to stacionary excitation. Report no. UCB/EERC-79/32. Earthquake Engineering Center, Univercity of California, Berkeley, California 1979.

[3] EN 1998-1: Design of structures for earthquake resistance. General rules, seismic actions and rules for buildings.

[4] EN 1998-1: Design of structures for earthquake resistance. Part 2: Bridges.

[5] Eurocode 8: Seismic design of buildings. Worked examples. JRC Scientific and Technical Reports, 2012.

[6] Gao X., Zhou X. Wang L.: Multi-Component Seismic Analysis for Irregular Structures. $13^{\text {th }}$ World Conference on Earthquake Engineering. Vancouver, Canada, 2004.

[7] Jinsuo N., Morante R. J.: Miranda M., Braverman J., On the Correct Application of the 100-40-40 Rule for Combining Responses due to Three Directions of Earthquake Loading. ASME PVP Conference, Bellevue, Washington, 2010.

[8] Lopez O. A., Hernandez J. J.: Structural Design for Multicomponent Seismic Motion. 13 ${ }^{\text {th }}$ World Conference on Earthquake Engineering. Vancouver, Canada, 2004.

[9] Lopez O. A. Hernandez J. J., Bonilla R., Fernandez A.: Propiedades de las tres components principales del movimiento sismico. Boletin Technico IMME, 2004.

[10] Menun C., Der Kiureghian A.: A Replacement for the 30\% Rule for multicomponent excitation. Earthquake Spectra, vol. 13, nr 1, 1998.

[11] Morante R.: Evaluation of Modal Combination Methods for Seismic Response Spectrum Analysis. 15th International Conference on Structural Mechanics in Reactor Technology, Seoul (KR), 1999. BNL-NUREG-66410.

[12] Nukala P. K.: Implementation of Modal Combination Rules for Response Spectrum Analy-sis. The University of California, National Technical Information Service, 1999, pp. 1-28.

[13] Projektowanie budynków podlegających wpływom wstrząsów górniczych. Instrukcja ITB nr 391, Warszawa 2003.

[14] Regulatory Guide 1.92, Combining Modal Responses and Spatial Components in Seismic Response Analysis. U.S. Nuclear Regulatory Commission, Washington, 2006.

[15] Tatara T.: Odporność dynamiczna obiektów budowlanych w warunkach wstrząsów górniczych. Wydawnictwo Politechniki Krakowskiej 2012. 
[16] Wdowicka E., Wdowicki J.: Algorytmy sumowania w metodzie spectrum odpowiedzi i ich wpływ na obliczoną odpowiedź budynku wysokiego. Jubileuszowe Sympozjum Dynamiki Konstrukcji, Rzeszów, 1999.

[17] Wilson E.L.: Three-Dimentional Static and Dynamic Analysis of Structures. Computers and Structures Inc., Berkeley, California 2002.

\section{DESIGNATION OF STRUCTURE MODAL RESPONSE FOR EARTHQUAKE MOTIONS WITH CONSIDERATION OF THEIR DIRECTIONALITY}

\section{S u m m a r y}

The paper presents calculation methods of modal response during the earthquake motions and some remarks of dynamic and spectral analysis. The most often methods used to combine effects of natural vibration modes and earthquake directions are considered. Authors presented well known Complete Quadratic Combination (CQC) and its newest modifications CQC3 for planar variability and General Complete Quadratic Combination (GCQC3) for spatial variability of earthquake directions. All calculation approaches are supported with two examples of steel frame structures submitted to earthquake effects according to Eurocode 8.

Keywords: seismic analysis, spectral analysis, quadratic combinations, multicomponent seismic motions, correlation of effects

Przestano do redakcji: 25.09.2016 $r$.

Przyjęto do druku: 31.03.2017 r. 